\title{
HAPPY 60th BIRTHDAY PROFESSOR KULENOVIĆ
}

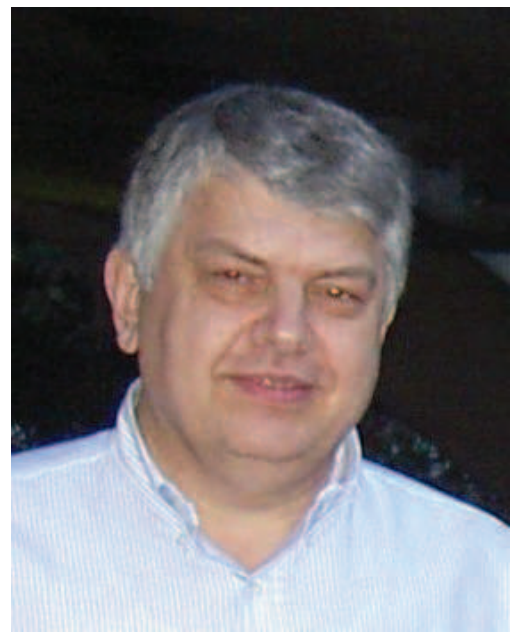

It is a great pleasure to congratulate one of our editors Professor Mustafa Kulenović on his 60th birthday and to dedicate this issue of our journal to him in honor of his many contributions to the fields of differential equations, difference equations and discrete dynamical systems. We want to thank him for his outstanding service to our university, mathematics and the cultural life in Bosnia and Herzegovina. His former and current doctoral students want to thank him for his generous assistance, great patience and warmth he has given us as our mentor.

Many authors, his colleagues and former students, have contributed to this edition, dedicating their papers to Professor Kulenović.

Mustafa R. S. Kulenović was born in Sarajevo on June 23, 1951. He graduated from the First Gymnasium in Sarajevo in 1970 and got his B. S. in Mathematics, from University of Sarajevo, Bosnia and Herzegovina in 1974 with highest honors. In 1977 he received his M. S. in Mathematics and in 1981 his Ph.D. in Mathematics, from University of Sarajevo, Bosnia and Herzegovina. He held positions of Assistant Professor at University of Sarajevo from 1982 to 1987, Associate Professor from 1987 to 1989 and Professor from 1990 to September 1994. He also held the positions of Visiting Assistant Professor at the University of Rhode Island from 1985 to 1986 and 1987 to 1989 and from 1984 to 2000 and Visiting Associate Professor 
at the American University of Cairo in 1989/1990. He was promoted to the position of Professor at the University of Rhode Island in 2006. He holds the position of Distinguished Professor at the University of Tuzla since 2008. In May of 2010 he received the Outstanding Research and Intellectual Property recognition from the University of Rhode Island.

Professor Kulenović served as major professor for nine PhD students, six in Bosnia and three in the USA and is currently advising three PhD students. He also served on the $\mathrm{PhD}$ commitees of $24 \mathrm{PhD}$ students. He has published two books and over 120 papers and some software packages. His research results are widely cited and he has more than 1600 citations in the Science Citation Index with over 1200 citations since 1998. He has more than 750 references in MathSciNet. Some of his papers are among the top one percent of the papers by citation in mathematics since 2000. Several papers has been in the top ten most downloaded papers or are in top ten most cited papers in some of the leading journals in discrete dynamical systems. So far, he had 44 co-authors and he has several more in sight.

The research interests of Professor Kulenović are in the theoretical and applied aspects of difference equations and discrete dynamical systems, including the global behavior of solutions. He worked in differential equations especially in the oscillation and the asymptotic behavior of delay differential equations, where, together with G. Ladas started an area known as the linearized oscillation theory. In the theory of difference equations, he initiated, together with G. Ladas, the systematic study of global dynamics of linear fractional difference equations. Today this area has more than 300 actively involved participants throughout the world.

Professor Kulenović has presented several lectures in major conferences on difference and differential equations held in the United States, Canada and Europe. He was twice an invited speaker for the World Congress of Mathematicians.

Professor Kulenović has served as Vice President of the Society of Mathematicians and Physicists of Bosnia and Herzegovina, 1983-1985, Chair for Applied Mathematics, University of Sarajevo, Bosnia and Herzegovina, 1984-1989 and Chairperson of Department of Mathematics University of Sarajevo, Bosnia and Herzegovina, September 1991-September 1994. He was the Coordinator for the curriculum development of mathematics in elementary school and high school in Bosnia and Herzegovina, 1992-94 and a Member of the Board of Directors of BIT - Bosnian Association for Information Technologies, 1992-94 and a Member of the Editorial Board of Acta Informatica Medica, Bosnia and Herzegovina, 1993-1994.

Professor Kulenović is a Member of the Editorial Board of the Sarajevo Journal of Matematics, formerly Radovi Matematički, Academy of Sciences 
of Bosnia and Herzegovina, Sarajevo and is also on the editorial board of six international journals. He has also served as the Referee for more than 30 mathematical journals such as Proceedings of American Mathematical Society, Transactions of American Mathematical Society, Journal of Differential Equations, Journal of Difference Equations and Applications, Nonlinear Analysis, Theory, Methods and Applications, Journal of Mathematical Analysis and Applications, Applied Mathematics Letters, Computers and Mathematics with Applications, etc.

Professor Kulenovic was the Co-organizer of the Special Session of the AMS Annual Meeting in four of the last five meetings and the co-organizer of the Special Session of the AMS Regional Meeting in four occasions. Since 1999, he delivered 32 talks in different international conferences, 17 invited talks in different universities and gave four graduate courses in different universities in Bosnia. In addition he taught many graduate courses in the USA.

Professor Kulenović has taught many courses, both undergraduate and graduate and received excellent student evaluations. He was also the Principal Investigator in several Research Projects in both Theoretical and Applied Mathematics financed by the Research Foundation of Bosnia and Herzegovina.

Most cited publications

1. M. R. S. Kulenović and G. Ladas, Dynamics of Second Order Rational Difference Equations, with Open Problems and Conjectures, Chapman\&Hall/CRC Press, 2001.

2. M. R. S. Kulenović and O. Merino, Discrete Dynamical Systems and Difference Equations with Mathematica, Chapman\&Hall/CRC Press, 2002.

3. C. H. Gibbons, M. R. S. Kulenovic and G. Ladas, On the recursive sequence $x_{n+1}=\left(\alpha+\beta x_{n-1}\right) /\left(\gamma+x_{n}\right)$, Math. Sci. Res. Hot-Line, 4 (2000), $1-11$.

4. M. R. S. Kulenović, G. Ladas and W. S. Sizer, On the recursive sequence $x_{n+1}=\left(\alpha x_{n}+\beta x_{n-1}\right) /\left(\gamma x_{n}+\delta x_{n-1}\right)$, Math. Sci. Res. Hot-Line, 2 (5) (1998), 1-16

5. K. Gopalsamy, M. R. S. Kulenović and G. Ladas, Environmental periodicity and time delays in a "food-limited" population model, J. Math. Anal. Appl., 147 (2) (1990), 545-555.

6. C. H. Gibbons, M. R. S. Kulenović, G. Ladas and H. D. Voulov, On the trichotomy character of $x_{n+1}=\left(\alpha+\beta x_{n}+\gamma x_{n-1}\right) /\left(A+x_{n}\right)$, J. Difference Equ. Appl., 8 (1) (2002), 75-92.

7. M. R. S. Kulenović and O. Merino, Global bifurcation for discrete competitive systems in the plane, Discrete Contin. Dyn. Syst. Ser., 12 (1) (2009), 133-149. 
8. E. Camouzis, M. R. S. Kulenovic, G. Ladas, and O. Merino, Rational systems in the plane, J. Difference Equ. Appl., 15 (3) (2009), 303-323.

9. M. R. S. Kulenović and M. Nurkanović, Asymptotic behavior of a two dimensional linear fractional system of difference equations, Dedicated to the memory of Prof. Dr. Naza Tanović-Miller, Rad. Mat., 11 (2002), $59-78$.

10. D. Clark, M. R. S. Kulenović and J. F. Selgrade, Global asymptotic behavior of a two-dimensional difference equation modelling competition, Nonlinear Anal. TMA, 52 (7) (2003), 1765-1776.

11. M. R. S. Kulenović, Invariants and related Liapunov functions for difference equations, Appl. Math. Lett., 13 (7) (2000), 1-8.

\section{Software}

1. Dynamica - computer package, written in Mathematica, intended for use in the study of difference equations and discrete dynamical systems. (with O. Merino) (software supplement of book 2).

We join the academic community in extending warm wishes and congratulations to Professor Kulenović on the occasion of his 60th birthday and also wish him good health, much happiness and long years of further activity as a scientist with many results. 